\title{
DESFAZENDO O MITO DO SUPER-HERÓI DOCENTE
}

\author{
Rogério Alencar Ferraz de Andrade
}

\section{RESUMO}

Este artigo procura investigar acerca da influência das concepções sociais sobre a figura do professor de Língua Materna como único responsável pela motivação dos alunos para a aprendizagem. Com uma breve introdução acerca do desenvolvimento da teoria da motivação pelas duas principais correntes psicológicas que situam a aprendizagem como centro de sua preocupação e uma análise das posturas defendidas pela teoria relacional de Joseph Nuttin e complementadas pela pedagogia simbólica junguiana, o artigo tenta descrever a importância dos fatores que normalmente são deixados de lado nos estudos comumente desenvolvidos. Trata-se da tentativa de voltar os olhares dos educadores para outros paradigmas essenciais na ordem do aprender e do significar a tarefa dos educadores entre si, com os alunos e com toda a sociedade.

\section{INTRODUÇÃO}

É mudando práticas que se reconfiguram os conceitos e refazem-se as concepções. Dessa perspectiva nasceu o presente artigo bem como o desafio de investigar as fontes da motivação para a aprendizagem de línguas. A opção ocidental pelo desprezo da subjetividade e uma ampla e declarada adesão ao experimental gerou dilemas complexos e aparentemente impossíveis de resolver. Ao dilema da motivação para a aprendizagem, que é o tema do presente artigo, acoplou-se, por exemplo, o mito do super-herói docente. Supõe-se que o êxito ou o fracasso dos alunos deve-se ao preparo do professor, que além do saber precisa conciliar empatia, criatividade, segurança e acima de tudo, pressupostos psicológicos capazes de prender a atenção dos educandos.

Uma análise detalhada da realidade contradiz as concepções que defendem tal postulado. Inúmeros professores bem preparados, criativos, capazes de chamar a atenção dos alunos em sala de aula fazem coro ao grupo dos educadores que reclamam das dificuldades em motivar os educandos para aprender e estudar a própria língua com suas nuances e particularidades. A conseqüência dessa realidade revela-se na limitação cultural que se expressa nas redações dos vestibulares e na linguagem monossilábica dos adolescentes e jovens. De outro lado, os professores sentem-se limitados carregando uma carga de culpabilidade imputada pela sociedade 
e sedimentada pelas constantes opiniões da mídia que não hesita em anunciar as limitações dos educadores.

Este artigo pretende elucidar outros fatores inerentes à motivação humana e que podem ajudar a re-significar a presença dos educadores em salas de aula, de forma a conciliar o mundo interno da escola e o mundo externo (que os educandos trazem consigo).

\section{CONTRIBUIÇÕES DA PSICOLOGIA}

Pesquisas realizadas pela psicologia puseram, em grande parte, os marcos para o estudo da motivação humana. Duas correntes configuram o divisor de águas entre as teorias e pesquisas desenvolvidas nesse campo. De um lado, os psicólogos que trabalham a partir das motivações ocasionadas pelas necessidades (positivas ou negativas) do organismo. Assim, Woodworth apud Nuttin (1978, p 114) trabalha as motivações a partir do plano das necessidades de percepção, pois para ele estamos inteiramente relacionados com o meio e dominados por móveis como o desejo de ver, ouvir, ver claramente, ouvir distintamente. Nessa mesma perspectiva situam-se Wundt com seus estudos acerca da fisiologia, posteriormente desembocando nos teóricos do comportamentalismo cujos representantes mais notáveis são Watson, Hull e Skinner, entre outros.

A perspectiva humanista, iniciada pela hierarquia de necessidades proposta por Maslow, influenciado pela antropologia, muda radicalmente sua perspectiva em relação ao estudo do ser humano. Nessa mesma perspectiva encontram-se as pesquisas de Kurt Lewin, que dá um passo adiante procurando entender o ser humano dentro do contexto em que o mesmo se encontra ou é gerado. Influenciado pelos psicólogos da Gestalt, Lewin centra nas necessidades e na personalidade o seu trabalho através da perspectiva social que atua sobre o comportamento das pessoas. E por essa mesma senda já havia trilhado o pensamento do russo Lev Semenovich Vygotsky, que empreendera seu estudo em busca das íntimas conexões entre a linguagem e o meio e as influências de ambos no processo de aprendizagem.

Há uma oscilação entre o orgânico (interno), também chamada motivação intrínseca, e o ambiental (externo), conhecido como motivação extrínseca. É em torno desse eixo 
que giram quase todas as obras de psicologia que enfocam o tema da motivação. Encontramo-la nessa condição em Gagné (1974), Campos (1979), Gauthier (1998), entre outros.

\subsection{CONTRIBUIÇÕES DA TEORIA RELACIONAL}

Na elaboração e explicitação de suas concepções acerca das motivações, Nuttin não despreza os espaços fisiológicos como portadores do impulso que impele o homem a agir. No entanto, não centra neles as suas perspectivas, pois para ele (1978, p. 130):

...É possível que o homem necessite alguma forma de relação social que the dê o sentimento de ser ou de significar algo para os outros ou, em outras palavras, uma necessidade de consideração pessoal.

E ainda em (1978, p. 137):

A motivação da personalidade constitui o elo central no processo de integração que une a civilização e a personalidade. Influenciada por algumas práticas sociais primárias a personalidade e suas tendências determinam por usa vez a estrutura das instituições culturais.

No entanto, para Nuttin, as motivações não permanecem apenas no campo do fenomenológico do homem, mas encaminham-se sobretudo para o campo das elaborações cognitivas de suas necessidades. Por isso, para ele (1978, p. 140-141): “...O estado de motivação não se manifesta somente no fato da execução de algumas atividades exteriores, mas também na elaboração de planos e projetos do que deseja fazer".

As motivações alcançam o nível mais profundo da realidade humana, que é a consciência e não param aí, manifestam-se através da linguagem, por vezes. Por isso, para o criador da Teoria Relacional o marco teórico do estudo da motivação não se centra no que, mas no como, isto é, na concepção que a pessoa tem de si mesma. Por isso afirma (1978, p. 146) que: "É a maneira de conceber a personalidade que impõe nossa concepção das necessidades e a motivação humana".

Com este marco, Nuttin inverte as perspectivas no estudo da motivação e o que antes era olhado de fora para dentro, agora é observado de dentro para fora. Trata-se de um olhar a partir do sujeito enquanto co-criador das necessidades a partir das 
necessidades que ele mesmo cria. Por isso, para ele o centro da motivação encontrase na personalidade e dinamiza-se através de dois pólos: eu/mundo e organismo/meio. $O$ conjunto de interações entre esses dois pólos é o dado primário que constitui a personalidade. A conduta é então reflexo da motivação e não o contrário. O autor confirma essa tese (1978, p 149) quando diz que a motivação:

...é o fator responsável do fato de que a conduta não consiste em atividades e contatos com qualquer objeto, mas que procura realizar certos tipos de relação com categorias de objetos que qualificamos de privilegiados, já que são os únicos que podem satisfazer ao organismo ou a personalidade.

Essas relações, no entanto, não acontecem por acaso, mas constroem-se no contato com o mundo de forma contínua. Por isso, a forma como conhecemos o mundo (quer via educação, quer via percepção) faz irromper as motivações e os comportamentos nas diferentes situações. Ele mesmo se pergunta, não acerca do que conhecemos pois isto é peremptório e de pouca valia para um estudo sistemático e metódico da motivação - mas acerca do como conhecemos. A conclusão a que chega é esta (1982, p 115):

\begin{abstract}
...como é que se constrói, progressivamente, esse arsenal de experiências cognitivas, de motivações e de orientações concretas, assim como esse dispositivo reacional, que entram como elementos materiais e formais no funcionamento da personalidade? É o problema da aprendizagem, concebida como processo geral do desenvolvimento da personalidade em função da experiência e da conduta anteriores, isto é, como enriquecimento e acabamento progressivos.
\end{abstract}

Nessa progressão e acumulação de saberes e motivações centra-se a teoria relacional, pois nenhuma conduta constrói-se no momento atual. Elas passam pela significação contida nas informações que os sentidos conduzem ao cérebro que irá distingui-las e valorá-las através das percepções. Entretanto, tais afirmações trazem em seu bojo antigos questionamentos, pois de certa forma, retomam a questão da autonomia no agir, uma vez que o ser humano não tem claro todos os elementos que o impelem a agir de determinada maneira. Nuttin não nega isso, ao contrário, resolve a questão ao relativizar a autonomia das ações. O que para ele não se trata de fazer tudo o que ser quer, mas de ser fiel ao desenvolvimento de inserção que a personalidade vai construindo com o mundo que a rodeia. 
A teoria relacional é um grande marco na história da psicologia e da própria aprendizagem, pois põe balizas ao que até então era tido como definitivo no campo das motivações humanas. $E$ esse fato tem incidências no campo da educação e especialmente no ensino da língua materna, pois até agora pouco tem sido feito para libertar o ensino de línguas da espiral behaviorista que procura partir dos influxos exteriores, o que não tem nenhum valor e nem pode alcançar as motivações intrínsecas que se sedimentaram em cada uma das personalidades dos educandos. Ora, tal teoria aponta para algo ainda mais sério: o processo de formação das motivações dos próprios educadores, pois este influenciará de forma direta suas práticas e, conseqüentemente, as relações estabelecidas com os educandos (o que pode trazer resultados positivos ou negativos, dependendo de variáveis como equilíbrio do professor, ambiente, disponibilidade material, etc).

Passamos a contruir aproximações de forma dialógica na interface da teoria relacional com a teoria interacionista de Vygotsky. Esta afirma a dinamicidade do processo de desenvolvimento quando defende que (2001, p. 409):

\footnotetext{
...a relação entre o pensamento e a palavra é, antes de tudo, não uma coisa, mas um processo, é um movimento do pensamento à palavra e da palavra ao pensamento. À luz da análise psicológica, essa relação é vista como um processo em desenvolvimento, que passa por uma série de fases e estágios, sofrendo todas as mudanças que, por todos os seus traços essenciais, podem ser suscitadas pelo desenvolvimento no verdadeiro sentido da palavra.
}

Esse desenvolvimento pode ser captado na própria linguagem, pois ela é o campo de realização do pensamento que colhemos nas práticas sociais e nos discursos estabelecidos como legítimos no campo da educação. Torna-se fundamental estudar a dinamicidade desse desenvolvimento conceitual e lingüístico dos educadores, tendo em vista as motivações construídas através do contato com o mundo e manifestado primeiro na concepção de si (teoria da personalidade) e posteriormente nas práticas pedagógicas.

\subsection{O EDUCADOR SUPER-HERÓI: UM MITO}

É inegável o papel do educador no processo de formação da motivação para o aprender. Não fosse assim, não haveria sentido que justificasse sua presença na escola. No entanto, a complexidade do mundo moderno exige um olhar aprofundado 
que tenha por escopo a análise dos diferentes fatores que interagem e influenciam não apenas o desenvolvimento das atividades em sala de aula, mas ainda as motivações dos educandos para dirigirem-se à escola e lá permanecerem durante um certo período de tempo para aprender.

Apesar da criatividade do educador ser fundamental como motivação extrínseca e inicial para a aprendizagem, não se pode prescindir das concepções que os educandos têm da escola, da disciplina em questão, dos professores e do futuro que os aguarda. E, nas concepções estabelecidas acerca do aprender, destaca-se a separação entre a emoção e a razão. É do senso comum que a escola geralmente é freqüentada não tanto pelo suposto gosto de estudar, mas principalmente pela necessidade de "nos tornarmos alguém". De acordo com Bohn apud Leffa (2001, p. 120): A separação do cartesianismo entre corpo e mente seja talvez a origem de um dos grandes problemas da escola de hoje: a falta de motivação dos alunos para a aprendizagem, fruto da ausência de emoção.

Sendo assim, a escola não convida para a criatividade, pois só pode estabelecer-se nela quem se adapta ao que ela propõe como sendo cultura. É assim que Bohn conclui a impossibilidade de haver motivação e criatividade onde não há espaço para a emoção, uma vez que nossas motivações provêm justamente dos sentimentos. "O novo só pode florescer se a mente estiver isenta de crenças, ideologias, dogmas restritivos. O sistema de crenças faz o filtro de nossa aprendizagem e de nosso ensino” (Bohn apud Leffa, 2000, p. 120). Partilha dessa posição o psicoterapeuta Byington, que insiste na importância das emoções enquanto parte integrante do ensino a ser considerada pelos educadores. "O saber motivado emocionalmente pode tornar-se uma das mais apreciadas atividades humanas.” (Byington, 2004, p. 30).

Existem ainda inúmeras outras variáveis que interferem na motivação para a aprendizagem de língua materna. Cada uma delas deve ser avaliada e estudada dentro do contexto em que estão inseridos os educadores e educandos. A rapidez do mundo pós-moderno, as atividades que os educandos desenvolvem fora da escola com as novas tecnologias de que dispõem em contraposição ao modelo sucateado de escolas que dispõem de pouca ou de nenhuma tecnologia, são exemplos da diversidade de reações diante da tentativa dos educadores em motivar os que lhes são confiados pelos pais e pela sociedade para aprender. Acrescente-se que as concepções de ensino de línguas (tornadas convenções sociais) segundo as quais: a) 
o professor deve saber tudo; e b) depende somente dele que os alunos aprendam e realizem competentemente as tarefas de um falante nativo, mostram-se distantes da realidade. Pois não são poucos os professores que, mesmo dispondo de excelente preparo e dinâmicas em sala de aula, não logram êxito em seus empreendimentos.

Há elementos que vão além do imediatismo pretendido com um conteúdo ou outro desenvolvido. Para Byington (2004, p. 30): "para o professor avaliar sua eficácia na aplicação desse ensino ele deve se perguntar sempre: 1) o que vou ensinar hoje inclui a sua utilização na vida? ... 2) essa aplicação tem importância na minha vida, na vida em geral?" Quer dizer que o educador precisa considerar não apenas o que, mas o por quê e o como vai ensinar. Tratam-se dos critérios da aplicabilidade e da utilidade.

No ensino da língua materna, tem-se discutido amplamente e de forma incisiva sobre a inutilidade do ensino da gramática pela gramática, no entanto, a prática tem demonstrado pouca criatividade e inovação e as rejeições dos estudantes continuam sendo encaradas a partir do paradigma do aluno-gênio (quando se interessa e faz tudo conforme o professor propõe) e/ou do professor-mágico (ou super-herói), que consegue a façanha de despertar o interesse dos educandos para a sua disciplina.

\subsection{A PEDAGOGIA SIMBÓLICA JUNGUIANA}

A pedagogia simbólica junguiana aponta a necessidade de compreender a significação dos conteúdos para a vida do educando, tendo em vista que não levar em conta esse aspecto torna os conteúdos estéreis e as pessoas alienadas. É o que afirma o psiquiatra Byington (2004, p. 23):

\footnotetext{
...o ensino de coisas não inseridas no contexto pragmático do aluno equivale à introdução de um carrapato no cérebro, que suga a memória e a inteligência para si, tirando-as da vida do aluno. A transmissão do ensino inútil propicia a alienação e o desperdício da inteligência existencial do aluno, do professor e da escola, bem como dos recursos de sua família e da sociedade que o custeia.
}

Com vistas a libertar-se das concepções estagnadas acerca da missão do educador como um transmissor de conceitos e regras, a pedagogia junguiana pretende inserir o aspecto emocional como centro da educação, de forma que os educadores considerem elementos tais como a empatia, a história de vida do educando e suas relações com a família e com o mundo que o cerca. Nesse sentido, esboça-se uma 
ponte entre a psicologia de Jung e a teoria de Nuttin na tentativa de apontar outros caminhos a serem observados doravante pelos docentes de língua materna. Isto se torna viável na medida em que a teoria relacional possibilita uma retomada de concepções e pré-concepções e mostra-nos a emergente necessidade de rever o papel dos educadores, de modo que sua tarefa recobre a justa medida e sua quota de participação na motivação dos educandos seja equacionada de forma a não superestimar nem subestimar as capacidades e obrigações dos educadores.

\section{CONSIDERAÇÕES FINAIS}

O desenvolvimento atual das concepções acerca das interferências inconscientes nas motivações humanas está sendo valioso auxílio para educadores repensarem seu papel e significado na escola e na sociedade. Enquanto muitos mantêm concepções estagnadas acerca dos papéis sociais que os indivíduos exercem, como se tudo devesse manter-se sempre da mesma maneira, outros decidem-se pela desafiadora tarefa de revisar posturas e práticas. Entre a perspectiva tradicional que encarava o professor como detentor do saber e a perspectiva laxista que concede ao professor o lugar do aniquilamento e da superficialidade situa-se a posição de quem se compromete em buscar alternativas para os problemas enfrentados pela escola e pela sociedade no sentido de viabilizar aos educandos caminhos que os ajudem a realizarem suas existências e construírem personalidades saudáveis e responsáveis.

A sociedade tem empurrado para a escola os problemas que não consegue resolver e a escola devolve-os muitas vezes sem ter sequer tomado conhecimento dos problemas que envolvem a cotidianidade dos educandos. Entre a escola e o educando há mais variáveis que se possa imaginar e isso é relevante no ensino da língua materna. A teoria relacional aponta para essa dimensão e ajuda-nos a levar em conta os conceitos firmados no inconsciente de cada indivíduo, afinal, a educação embora coletiva, dá-se de forma individual, pois as relações atingem diretamente a pessoa envolvida com a educação. A teoria de Nuttin mostra-nos que já não é mais suficiente situar a motivação entre o intrínseco e o extrínseco, pois nem sempre dependem do querer e nem sempre são conscientes. E a psicoterapia junguiana auxilia-nos no sentido de entender as diferentes matrizes conceituais formadas no inconsciente das pessoas através das vivências. É preciso captar na linguagem e nas 
práticas dos educadores e educandos as diferentes concepções advindas dos contatos que travamos constantemente com outras pessoas.

Para se desfazer o mito do professor super-herói é mister levar em consideração as formas como cada educando concebe o mundo com vistas a investigar a possibilidade de interferências dessas concepções no desenvolvimento eficaz da aprendizagem de língua materna.

\section{BIBLIOGRAFIA}

BAQUERO, Ricardo. Vygotsky e a aprendizagem escolar. Ed. Artes Médicas, POA: 1998.

BYINGTON, Carlos Amadeu Botelho. A construção amorosa do saber. W11 editores, SP: 2004.

GAGNÉ, Robert M. Como se realiza a aprendizagem. Ed. Livros técnicos e científicos AS, RJ: 1974.

NUTTIN, J. La motivación. Ed. Nueva Visión, Buenos Aires: 1978.

. Estudos de Motivação Humana. Consciência, comportamento e personalidade. Ed. Livraria Duas Cidades, SP: 1982.

PEREZ SERRANO, Maria da Glória. Investigación-accion. Aplicaciones al campo social y educativo. Ed. Dykinson, Madrid: 1990.

PORLÁN, Rafael; RIVERO, Ana. El conocimiento de los profesores. Díada Editora, Sevilla: 1998.

RICHTER, Marcos Gustavo. Pedagogia de Projeto no Ensino do Português. Polígrafo $S / D$

. Pedagogia de Projeto. Santa Maria, Ed. UFSM, S/D.

SCHULTZ \& SCHULTZ. História da Psicologia Moderna, 16a. ed. Ed. Cultrix, São Paulo: 1981.

TOCHÓN, François Victor. A Língua como Projecto Didático. Porto Editora, Portugal: 1995.

VIGOTSKI, L. S. A construção do pensamento e da Linguagem. Martins Fontes Editora, São Paulo: 2001. 